Acta vet. scand. 1977, 18, 442-450.

From the Department of Microbiology and Immunology, Veterinary College of Norway, Oslo.

\title{
DEOXYRIBONUCLEASE INHIBITORY ACTIVITY IN PIG INTESTINAL CON,TENTS
}

\author{
By \\ Eivind Liven
}

LIVEN, E.: Deoxyribonuclease inhibitory activity in pig intestinal contents. Acta vet. scand. 1977, 18, 442-450. - The inhibitory effect of pig intestinal contents on some microbial DNases and bovine pancreas DNase was examined employing an agar diffusion test. The molecular weight of 1 inhibitor as well as the electrophoretic patterns of the inhibitors were determined.

DNases from Staphylococcus aureus, Staphylococcus epidermidis, Streptococcus pyogenes, Clostridium perfringens and bovine pancreas were inhibited by intestinal contents. DNases from Clostridium septicum, Serratia marcescens, Proteus mirabilis, Aeromonas hydrophila and Pseudomonas aeruginosa were not inhibited. The concentrations of the inhibitory substances were considerably higher in contents from the small intestine than from the large intestine.

Using electrophoretic procedures on intestinal contents, 3 different fractions showing DNase inhibition were demonstrated. The molecular weight of one of the inhibitors was estimated to be about 30000 .

deoxyribonuclease inhibitor; microbial DNase; animal D Nase; intestinal contents; pig.

Since Dabrowska et al. (1949) demonstrated the presence of an inhibitor against deoxyribonuclease (DNase) in the crop of pigeons, numerous authors have isolated and characterized corresponding inhibitors from various animal tissues (Cooper et al. 1950, Feinstein 1960), including intestinal mucosa. In most of the reports, the DNase activity has been tested, viscometrically or spectrophotometrically, in the absence and presence of extract from the various organs/tissues. In cases of reduced enzyme activity this has been considered to be due to 1 single inhibitor. Only Lindberg (1966) indicated the presence of several inhibitors against DNase I. In 1974 Lazarides \& Lindberg showed that actin isolated from different tissues, both of muscular and nonmuscular origin, possessed DNase-inhibiting activity.

In this paper, the inhibitory activity in intestinal contents of pigs against microbial DNases and bovine pancreas DNase is 
described. The electrophoretic patterns of this inhibitory activity are also presented.

\section{MATERIAL AND METHODS}

\section{Inhibitor-containing material}

Intestinal contents were collected from normal slaughter pigs (about $80 \mathrm{~kg}$ slaughter weight). Samples were taken from the upper (a), upper middle (b), lower middle (c) and the lower part (d) of the small intestine and from the colon (e). Intestinal contents were prepared as described by Liven (1976) and further fractionated by $80 \%$ saturation with $\left(\mathrm{NH}_{4}\right)_{2} \mathrm{SO}_{4}$. The precipitate was suspended in small amounts of distilled water and finally dialysed against running tap water for $20 \mathrm{hrs}$.

\section{Enzymes}

DNases from the following organisms were used: Staphylococcus aureus $\mathrm{NVH}^{\star}$ 19, Staphylococcus epidermidis NVH 2360, Streptococcus pyogenes NVH 218, Clostridium perfringens NVH 3183, Clostridium septicum NVH 3184. Proteus mirabilis NVH 2674, Serratia marcescens NVH 2672, Aeromonas hydrophila, (Aeromonas proteolytica ATCC $15338^{\star \star}$ ) and Pseudomonas aeruginosa NVH 150.

DNase I from bovine pancreas was obtained from Sigma ${ }^{\star \star}$, and used in a concentration of $0.5 \mathrm{mg}$ per $\mathrm{ml}$.

With the exception of the clostridial DNases, microbial DNases were produced on semi-solid skimmilk agar, according to the principles for production of proteinases published by Sandvik (1962). DNases from the Clostridium spp. were produced on Robertson's medium. Flasks containing $400 \mathrm{ml}$ medium were inoculated with $5 \mathrm{ml}$ liquid of a $24 \mathrm{hr}$. culture of the organisms on Robertson's medium. The flasks were incubated at $37^{\circ} \mathrm{C}$ for $24-48 \mathrm{hrs}$. anaerobically. After centrifugation at $16000 \times \mathrm{g}$ for 15 min., the supernatants were treated in the same way as the supernatants of the other organisms listed.

Enzyme solutions were stored at $-20^{\circ} \mathrm{C}$ until use.

* NVH: The culture collection at the Department of Microbiology and Immunology, Veterinary College of Norway.

* ATCC: American Type Culture Collection, Rockville, Maryland, USA.

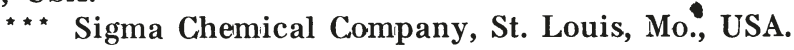




\section{Agar medium for detection of DNases}

Toluidine blue deoxyribonucleic acid agar (TDA) (Lachica et al. 1971) was used for detecting DNase activity. The activity of DNases in the TDA medium results in distinct bright pink areas in contrast to the otherwise blue medium. The medium was poured into glass trays to a depth of $2 \mathrm{~mm}$ and allowed to solidify.

\section{Demonstration of DNase inhibitory activity}

For the demonstration of inhibitory activity in intestinal contents, the method described by Sandvik (1974) was used. Filter paper strips moistened with intestinal contents were placed on the surface of the TDA. After $3 \mathrm{hrs}$. at $37^{\circ} \mathrm{C}$ the strips were removed, and strips moistened with the various enzyme solutions were placed at right angles to the direction of application of the intestinal contents. The plates were incubated at $37^{\circ} \mathrm{C}$ for $20 \mathrm{hrs}$. The presence of inhibitors was indicated by a narrowing of the pink zones along the enzyme-containing strips. Due to low DNase activity, some of the enzyme solutions were applied into $2 \mathrm{~mm}$ wide troughs in the TDA.

A semi-quantitative measure of the inhibitory activity was obtained by making serial two-fold dilutions of intestinal contents in distilled water and determining the highest dilution which inhibited DNase activity.

Intestinal contents were subjected to paper electrophoresis. The equipment and procedure for electrophoresis was as described by Sandvik, with the modification that the buffer was $0.05 \mathrm{M}$ veronal buffer, $\mathrm{pH} 8$.

\section{Molecular weight determination of DNase inhibitor}

The molecular weight of 1 inhibitor was determined by gel filtration. A column $(1.40 \times 90 \mathrm{~cm})$ of Sephadex G-100 in $0.1 \mathrm{M}$ acetate buffer, $\mathrm{pH} \mathrm{6}$, containing $0.4 \% \mathrm{NaCl}$, was calibrated with bovine serum albumin, pepsin, trypsin and soybean trypsin inhibitor. The void volume was determined with Blue Dextran2000. Precipitated intestinal contents were suspended in an equal volume of the column buffer and filtered through a cellulose triacetate membrane filter ${ }^{\star}(0.2 \mu \mathrm{m})$. One $\mathrm{ml}$ of the filtrate was used for gel filtration. The presence of DNase inhibitor in the

\footnotetext{
* Gelman Instrument Company, Ann Arbor, Michigan, USA.
} 
eluted fractions was demonstrated by the method used for the detection of DNase-inhibitors in intestinal contents.

\section{RESULTS}

Figure 1 shows the effect of the intestinal contents on some microbial DNases and bovine pancreas DNases. In general, contents from the small intestine inhibited DNases from Staphylococcus spp., Streptococcus pyogenes, Clostridium perfringens and from bovine pancreas although some variation among the samples was observed. Inhibitory activity against staphylococcal, streptococcal and bovine pancreas DNases was constantly pre-

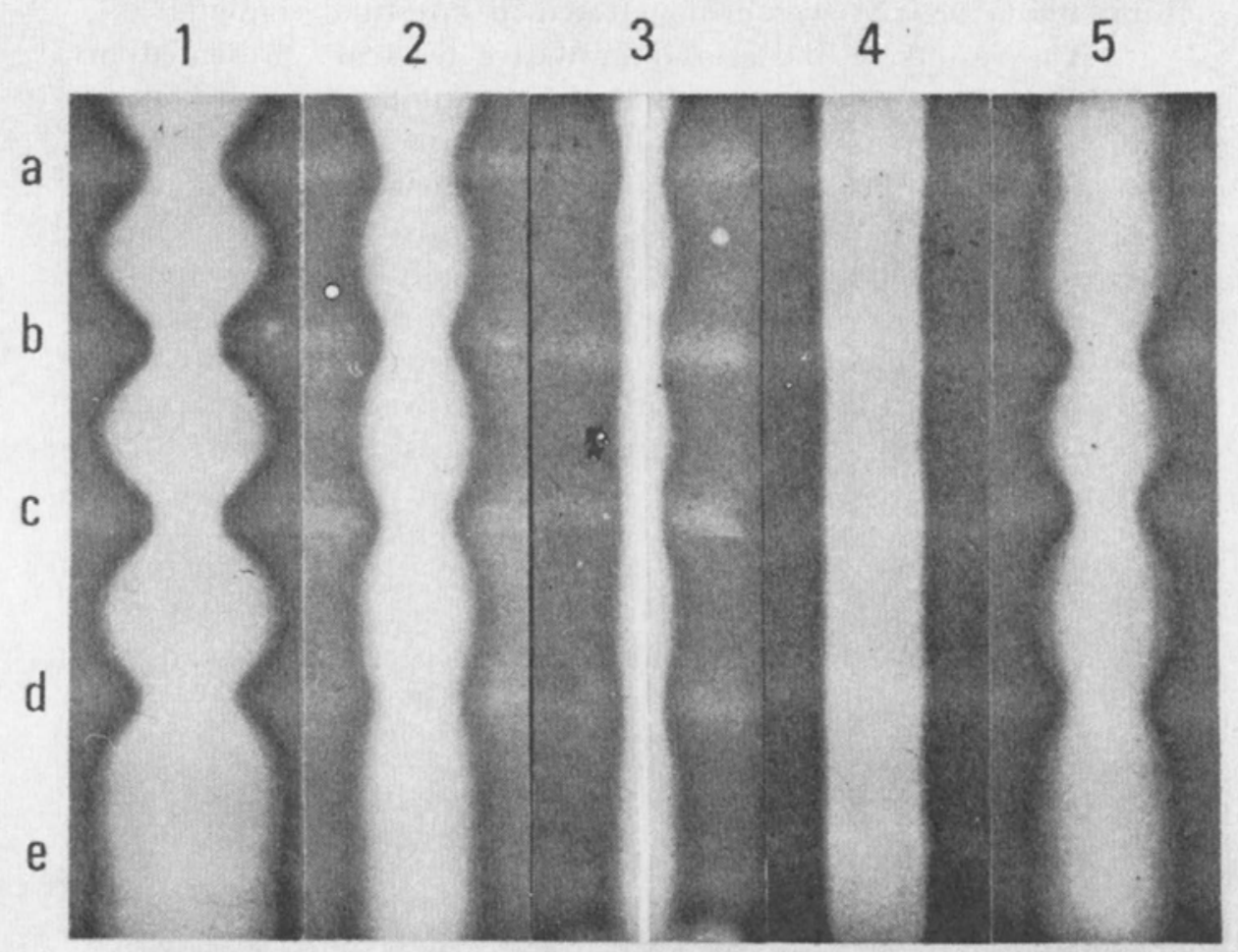

Fig u r e 1. Effects of intestinal contents on the activity of DNases of various origins. Intestinal contents were from the upper (a), upper middle (b), lower middle (c) and the lower part of the small intestine (d) and from colon (e). DNases were produced from Staphylococcus aureus (1), Streptococcus pyogenes (2), Clostridium perfringens (3), Serratia marcescens (4) and bovine pancreas (5). 
sent in samples $b, c$ and $d$, while against Clostridium perfringens DNase, inhibition was more infrequently seen in these samples. In about $20 \%$ of the samples from the upper small intestine (sample a) investigated, inhibition was not demonstrated against any of the DNases used. In contents from the large intestine (sample e), inhibition against staphylococcal DNases was present in approx. $80 \%$ of the samples, against bovine pancreas in $50 \%$, and against streptococcal DNases in about $20 \%$ of the samples. Contents from the large intestine showed no inhibitory activity against DNase from Clostridium perfringens. Towards DNases from Clostridium septicum, Proteus mirabilis, Serratia marcescens, Aeromonas hydrophila and Pseudomonas aeruginosa, no inhibitory activity was demonstrated in intestinal contents.

The results of the semi-quantitative tests are presented in Table 1. The mean concentrations of the inhibitors were highest in the lower part of the small intestine. Only against DNases from Staphylococcus aureus could equivalent concentrations be demonstrated in the upper part of the intestine. In the large intestine, the inhibitory activity was markedly reduced compared with the activity in the small intestine. In all parts of the intestines investigated, the mean concentration of the inhibitory activity against Staphylococcus aureus DNase was markedly higher than the inhibitory activity towards the other DNases tested.

The electrophoretic patterns of the inhibitors are shown in

T a ble 1. Mean titre of DNase inhibitors in intestinal contents from different locations in the intestinal tract. The origin of intestinal contents is described in legend to Fig. $1(\mathrm{a}-\mathrm{e})$. The titre is expressed as the reciprocal of the dilution.

\begin{tabular}{lccccr}
\hline Origin of enzymes & \multicolumn{5}{c}{ Mean titre } \\
\cline { 2 - 6 } & $\mathrm{a}$ & $\mathrm{b}$ & $\mathrm{c}$ & $\mathrm{d}$ & $\mathrm{e}$ \\
\hline $\begin{array}{l}\text { Staphylococcus } \\
\text { aureus }\end{array}$ & 185 & 390 & 358 & 390 & 39 \\
$\begin{array}{l}\text { Staphylococcus } \\
\text { epidermidis }\end{array}$ & 23 & 85 & 93 & 134 & 4 \\
$\begin{array}{l}\text { Streptococcus } \\
\text { pyogenes }\end{array}$ & 6 & 19 & 30 & 35 & 1 \\
$\begin{array}{l}\text { Clostridium } \\
\text { perfringens }\end{array}$ & 0.2 & 2.4 & 6.5 & 4.7 & 0 \\
Bovine pancreas & 29 & 44 & 69 & 57 & 2.2 \\
\hline
\end{tabular}


Fig. 2. Generally 3 different zones (I, II, III) of inhibitory activity were demonstrated. However, against DNase from Clostridium perfringens inhibitory activity was never detected in any of the zones.

In zone I inhibitory activity against staphylococcal, streptococcal and bovine pancreas DNases was consistently found in contents from the small intestine. Inhibitory activity against staphylococcal and bovine pancreas DNases appeared as a broad band occasionally divided in 2 parts as indicated in Fig. 2. In contents from the large intestine inhibition was found against

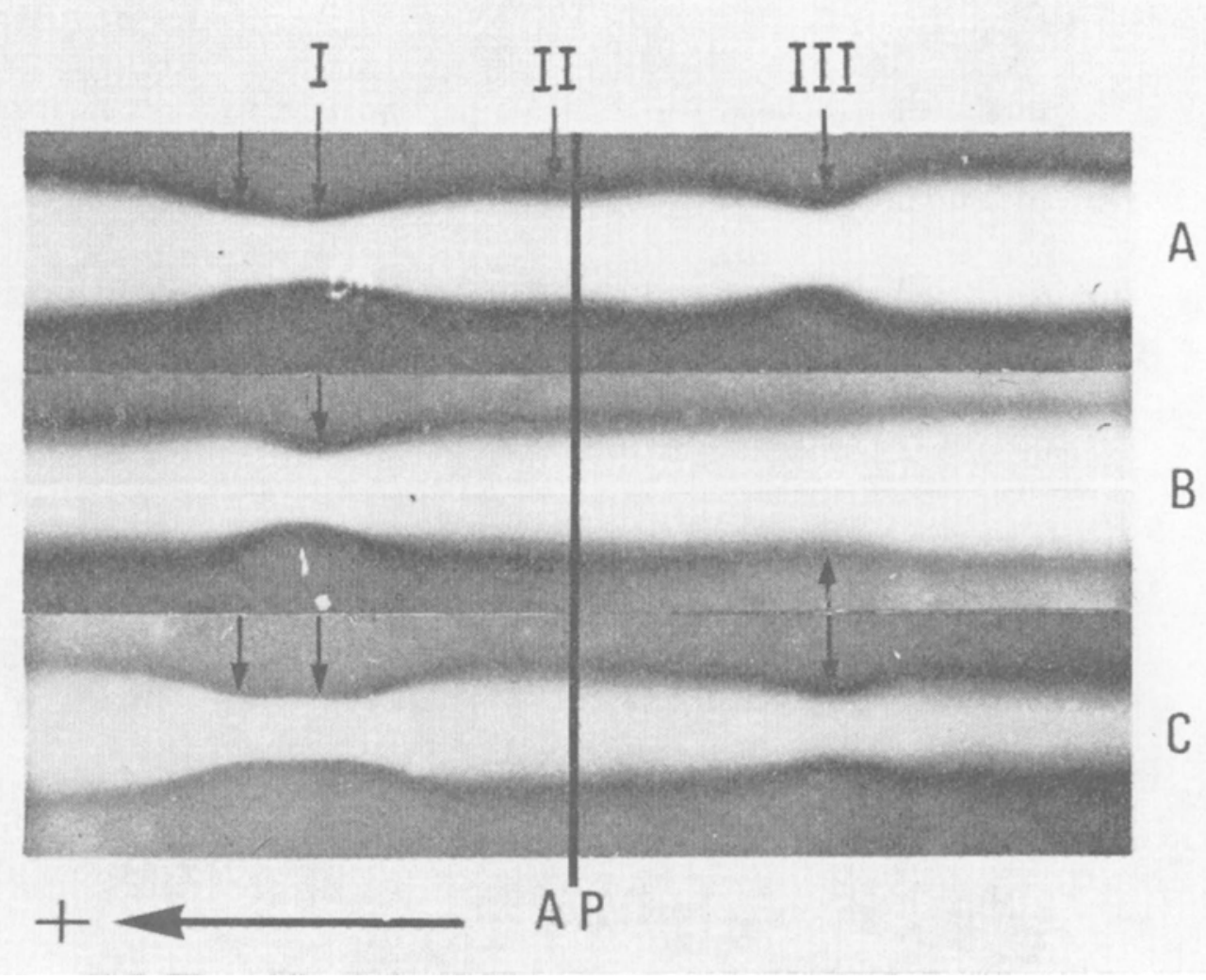

Figure 2. Electrophoretic pattern of the various DNase inhibitory substances in small intestinal contents. The DNases used are those from (A) Staphylococcus aureus, (B) Streptococcus pyogenes and (C) bovine pancreas. The electrophoretically distinguishable inhibitors are denoted I, II and III, and the zones of inhibition are marked by arrows. The electrophoresis was carried out in $0.05 \mathrm{M}$ veronal buffer at $\mathrm{pH} 8$ for $18 \mathrm{hrs}$. at $120 \mathrm{v}$. AP: Line of application. 
staphylococcal and pancreas DNases, but not against streptococcal DNase.

In zone II both in contents from the small and large intestine inhibitory activity was demonstrated against staphylococcal DNases and occasionally against bovine pancreas DNase. Streptococcal DNase was never inhibited in this zone.

In zone III inhibitory activity in contents from the small intestine was regularly found against staphylococcal and bovine pancreas DNases, and occasionally against streptococcal DNase. In this zone contents from the large intestine consistently inhibited bovine pancreas DNase and usually staphylococcal DNases as well. Inhibition of streptococcal DNase from the large intestinal contents was never demonstrated in this zone.

The gel filtration procedure showed that the inhibitory activity was eluted from the column in 1 single peak, indicating that the inhibitor had a molecular weight of approx. 30000 .

\section{DISCUSSION}

This investigation indicates that intestinal contents from healthy pigs possess inhibitors against some microbial DNases and bovine pancreas DNases. It also shows that these inhibitors are present in highest concentrations in the lower part of the small intestine; that they are most active against staphylococcal DNases and that they can be separated into several fractions by electrophoresis.

The presence of DNase inhibitors in gastrointestinal mucosa has been reported by several workers. Consequently, the probability of a mucosal origin for the inhibitory activity demonstrated is high. However, bearing in mind that also blood cells contain DNase inhibitors (Gupta \& Herriott 1963) which may be released into serum (Herriott et al. 1961), it is possible that blood cells also contribute to the DNase inhibitory activity in intestinal contents.

In 1974, Sandvik demonstrated the presence of antibodies in blood sera against staphylococcal DNases in healthy animals. The inhibitors demonstrated in this study could have been antibodies secreted into the intestinal lumen. However, it seems unlikely that antibodies to such an extent as demonstrated in this investigation could react with antigens as different as microbial and animal DNases. The results of the gel filtration indi- 
cating a molecular weight of approx. 30000 also exclude the possibility of antibody secretion.

The major part of the DNase-inhibitors are found in the lower part of the small intestine. The dramatic reduction of the inhibitory activity in contents from the large intestine is also interesting. These findings do not necessarily indicate that the inhibitors are specifically released into the lumen in this special part of the intestine. The phenomenon could be caused by the existence of optimal conditions for the demonstration of the inhibitors from this region. It could also be due to inactivation of the inhibitors in other parts of intestines.

Using the electrophoretic procedure, none of the samples showed inhibitory activity against Clostridium perfringens DNase. Samples from the large intestine behaved similarly towards streptococcal DNase. The concentrations of the inhibitors against these DNases were very low, and it is probable that the amount of material used was too small to demonstrate the inhibitors with this method.

The inhibitory activity against only 1 category of animal DNases was tested in this study. It will be of interest to examine whether other animal DNases are also inhibited, especially porcine pancreas DNase. However to do this it would be necessary to separate the inhibitors from the DNases normally present in intestinal contents, otherwise the DNases in the samples would conceal the effects of the inhibitors. Pig intestinal DNases cannot be detected with the TDA medium used in this experiment (Liven 1976) and consequently, the DNases had no influence on the demonstration of the inhibitors in the samples. In contents from the small intestine in pigs, Liven \& Staveland (1976) found higher and lower DNase activity in regions which, in the present experiment, proved to have low and high concentrations of DNase inhibitors respectively. This correspondence could indicate that inhibitors demonstrated in pig intestinal contents can also act against the pigs' own intestinal DNases.

\section{REFERENGES}

Cooper, E. J., M. L. Trautmann \& M. Laskowski: Occurrence and distribution of an inhibitor for desoxyribonuclease in animal tissues. Proc. Soc. exp. Biol. (N.Y.) 1950, 73, 219-222.

Dabrowska, W., E. J. Cooper \& M. Laskowski: A specific inhibitor for desoxyribonuclease. J. biol. Chem. 1949, 177, 991-992. 
Feinstein, R. N.: Activation of the neutral deoxyribonuclease. J. biol. Chem. 1960, 235, 733-737.

Gupta, S. \& R. M. Herriott: Nucleases and their inhibitors in the cellular components of human blood. Arch. Biochem. 1963, 101, 88-95.

Herriott, R. M., J. H. Connolly \& S. Gupta: Blood nucleases and infectious viral nucleic acids. Nature (Lond.) 1961, 189, 817-820.

Lachica, R. V. F., C. Genigeorgis \& P. D. Hoeprich: Metachromatic agar-diffusion methods for detecting staphylococcal nuclease activity. Appl. Microbiol. 1971, 21, 585-587.

Lazarides, E. \& U. Lindberg: Actin is the naturally occurring, inhibitor of deoxyribonuclease I. Proc. nat. Acad. Sci. (Wash.) 1974, 71, $4742-4746$.

Lindberg, M. U.: Crystallization from calf spleen of two inhibitors of deoxyribonuclease I. J. biol. Chem. 1966, 241, 1246-1249.

Liven, E.: The applicability of agar-diffusion test in measuring deoxyribonucleases in pig intestinal content. Acta vet. scand. 1976, 17, $244-254$.

Liven E. \& K. Staveland: Single cell protein in the diets of pigs and chickens. Effects on the activity of DNase in intestinal contents. Acta vet. scand. 1976, 17, 441-450.

Sandvik, O.: Studies on casein precipitating enzymes of aerobic and facultatively anaerobic bacteria. Thesis. Veterinary College of Norway, Oslo 1962, 116 pp.

Sandvik, $O .:$ The occurrence of antibodies against staphylococcal deoxyribonucleases in blood sera from different species. Acta vet. scand. $1974,15,631-635$.

\section{SAMMENDRAG}

Hemningsaktivitet $i$ tarminnhold hos gris overfor deoxyribonukleaser.

Den hemmende virkning av tarminnhold fra gris overfor enkelte mikrobielle DNaser og bovin pankreas DNase ble unders $\varnothing$ kt ved å benytte en agar-diffusjonstest. Molekylvekten av en av inhibitorene samt inhibitorenes elektroforetiske mønster ble også bestemt.

DNaser fra Staphylococcus aureus, Staphylococcus epidermidis, Streptococcus pyogenes, Clostridium perfringens og bovin pankreas ble hemmet av tarminnhold, mens DNaser fra Clostridium septicum, Serratia marcescens, Proteus mirabilis, Aeromonas hydrophila og Pseudomonas aeruginosa ikke ble hemmet. Konsentrasjonen av de hemmende komponenter var vesentlig høyere $i$ innhold fra tynntarmen enn fra tykktarmen.

Ved elektroforese påvistes 3 forskjellige fraksjoner som viste DNase-hemning. Molekylvekten til en av inhibitorene ble bestemt til ca. 30000 .

(Received May 23, 1977).

Reprints may be requested from: Eivind Liven, Department of Microbiology and Immunology, Veterinary College of Norway, P. O. Box 8146, Oslo Dep., Oslo 1, Norway. 